\title{
People with dementia in long-term care facilities: an exploratory study of their activities and participation
}

\author{
Vânia Rocha1, Alda Marques1,2, Margarida Pinto1,2, Liliana Sousa2,3, and Daniela Figueiredo1,2 \\ 1School of Health Sciences, University of Aveiro (ESSUA), Aveiro, Portugal, 2Unidade de Investigação e Formação \\ sobre Adultos e Idosos (UniFAI), Porto, Portugal and 3Department of Health Sciences, University of Aveiro (SACS), \\ Aveiro, Portugal
}

\section{ABSTRACT}

Purpose: To describe the activities and participation of people with dementia living in long-term care facilities.

Methods: An exploratory descriptive study with 329 people medically diagnosed with dementia was conducted in the central region of Portugal. Socio-demographics were collected with a questionnaire based on the ICF-Checklist. Cognitive impairment was measured with the Mini-Mental State Examination and the activities and participation were described with the World Health Organisation Disability Assessment Schedule 2.0 (WHODAS 2.0).

Results: Participants mean age was $83.6 \pm 7.1$ years old. Most were female $(79.6 \%)$, widows $(60.8 \%)$, had 1 to 4 years of education (51.1\%) and were living in a long-term care facility from 2 to 4 years $(36.2 \%)$. Alzheimer's disease (41.9\%) was the most prevalent type of dementia. According to the MMSE, the cognitive status was low $(8.7 \pm 7.9)$ and $61.7 \%$ had severe cognitive impairment. The MMSE scores were negatively correlated with the WHODAS 2.0 scores. Mobility was the most affected domain of WHODAS 2.0. The total score showed that $77.8 \%$ of the sample was severely limited in activities and restricted in participation.

Conclusions: This study shows that people with dementia living in long-term care facilities have severe activities limitation and participation restriction. However, most residents understand what people say, eat by themselves and get along with people who are close to them. This information on disability is crucial to plan health resources and inform rehabilitation programmes tailored to individuals' functionality.

\section{INTRODUCTION}

Dementia has been considered a public health problem [1], as it is the most common chronic health condition and the major cause of disability and mortality among older people [2]. Dementia affects 35.6 million people worldwide [3]. This number will probably double every 20 years to 65.7 
million in 2030 and 115.4 million in 2050 [4]. Additionally, it contributes for $11.2 \%$ of years lived with disability in people aged 60 years old and older, more than stroke (9.5\%), musculoskeletal disorders (8.9\%), cardiovascular disease (5\%) and all forms of cancer (2.4\%) [5].

Some studies have been exploring functioning and disability of people with dementia [6-8], as data on the general state of this population is required to plan the resources needed for their care [9]. However, as highlighted in the World Report on Disability [10], more robust evidence is needed to inform decisions on policies and rehabilitation programmes [10], mainly in long-term care facilities where people with dementia are not always seen as having potential for rehabilitation [11]. An holistic perspective of the person through a multidimensional assessment has been recommended $[10,12$, 13] to guide rehabilitation and inspire future research. This multidimensional assessment allows person-centred rehabilitation [14], considering individual's activities and participation. However, previous research on activities and participation involving people with dementia has not considered an holistic assessment of the person and have used one-dimensional instruments, such as the Activities of Daily Living scale, Katz index and the Barthel index $[6,7]$. This is therefore a limitation to plan and deliver integrated and comprehensive care $[15,16]$.

The World Health Organisation Disability Assessment Schedule 2.0 (WHODAS 2.0) may overcome this limitation as it is an activities and participation multidimensional instrument direct linked to the International Classification of Functioning, Disability, and Health (ICF) [17]. ICF is a framework to describe functionality and disability at both the individual and population levels [18] and supports rehabilitation through resident-centred meaningful interventions [19]. The WHODAS 2.0 has been widely used in older people [20-22] however, little explored in older people with dementia [23]. Therefore, this study aimed to describe activities and participation of people with dementia living in long-term care facilities.

\section{METHODS}

\section{Design and ethics}

An exploratory descriptive study was conducted in the central region of Portugal during an eightmonth period (from December 2010 to July 2011). Ethical approval was previously obtained by the Ethics Committee of the Research Unit of Health Sciences at the Health School of Nursing in Coimbra, Portugal. Written informed consents were collected from the legal representatives of the people with dementia and from the formal caregivers. 


\section{Participants}

Fifty-seven long-term care facilities were contacted and information about the study was provided to the service managers in an arranged meeting. Forty facilities agreed to participate. Individuals whose medical diagnosis was irreversible dementia, according to DSM-IV criteria [24] and were living in the long-term care facility for at least three months, were identified by the service managers supported by the physician diagnostic. Potential participants were excluded if: i) refused to answer to the Mini-Mental State Examination (MMSE); ii) were severe or total sightseeing and/or severe hearing impaired; iii) had been at the long-term care facility for less than 3 months (considered the minimum individual time needed to adjust to the facility dynamics); iv) did not have a legal representative to sign the written informed consent; v) or died during the data collection period.

The service managers have also identified formal caregivers to provide information as part of the people with dementia assessment. Formal caregivers were eligible if they provided regular basic care to people with dementia, such as feeding, hygiene, dressing among others and worked at the institution for at least six months. Temporary workers, trainees and caregivers working only on the night shift were excluded, as they spend short periods of time with the residents.

In the 40 facilities, there were 353 residents with dementia and 163 caregivers that fulfilled the inclusion criteria. However, 24 residents were excluded as they: i) refused to answer to the MMSE $(n=4)$ or their family did not sign the written informed consent $(n=2)$; ii) were severe or total sightseeing $(n=4)$ and/or severe hearing impaired $(n=2)$; iii) have not been at the institution for at least 3 months $(n=6) ; v)$ or died during the data collection $(n=10)$. Therefore, a total of 329 people with dementia and 163 caregivers were recruited. The average ratio was 1 caregiver for 2 residents with dementia.

\section{Measures}

The Mini-Mental State Examination [25] adapted to the Portuguese population [26] was applied to assess participants' cognitive status. Moreover, the severity of cognitive impairment was also characterised based on the scores proposed by European studies, i.e., 27-21 mild, 20-11 moderate and $10-0$ severe $[27,28]$.

Activities limitation and participation restriction were assessed with the 36-item Portuguese proxy version of WHODAS 2.0 [29] which was answered by the formal caregivers, as recommended by WHO [13]. This instrument was chosen as it follows the same conceptual basis of the ICF [17] and it is multidimensional, i.e., captures the level of functionality in six major life domains: (i) cognition; (ii) 
mobility; (iii) self-care; (iv) getting along with people; (v) life activities (i.e., household activities, work or school activities) and (vi) participation [13]. Items are answered in a five-point Likert scale: 1-none; 2mild; 3-moderate; 4-severe; 5-extremely or cannot do, which grades the difficulty experienced by the participant in performing a given activity.

The 36-item version [29] was used, excluding the following items: i) D3.4 - "staying by himself or herself for a few days?", as people with dementia in long-term care facilities are not supposed to stay by themselves for days; and ii) D4.5 - "Sexual activities?", as caregivers did not consider they could answer to this question. The domain 5 was also excluded since people living in the long-term care facility had no household activities assigned to them (D5.1 to D5.4) and were not employed (D5.5 to D5.8).

The WHODAS 2.0 items illustrate the level of disability per question, domain and total score of a given sample. The total score of disability was obtained following the three steps reported by the World Health Organization [13], i.e., first, the recoded item scores within each domain were sum; then, the scores of the six domains were sum; and finally, the total score was converted into a metric scale ranging from 0 to 100 .

\section{Data collection}

Socio-demographics of people with dementia were first collected with a structured questionnaire based on the ICF Checklist [30]. It included gender, date of birth, education, marital status and admission date in the care facility. The researchers (i.e., a gerontologist or a physiotherapist) fulfilled the structured questionnaire using information from the clinical files and/or through conversation with the staff (health professionals, service managers, formal caregivers) of the long-term care facilities. Then, face-to-face interviews to people with dementia and to their formal caregivers were carried out separately. The interview to each person with dementia aimed to fulfill the MMSE and lasted on average $9.0 \pm 6.1$ minutes, depending on the severity of the cognitive impairment. The interview to each formal caregiver with the WHODAS 2.0 aimed to assess activities limitation and participation restriction of each person with dementia, and lasted on average $25.5 \pm 10.2$ minutes.

\section{Data Analyses}


Statistical analysis was performed using the PASW Statistics version 18.0 for Windows (SPSS Inc., Chicago, Illinois). Descriptive statistics were applied to all variables to characterise the sample.

The WHODAS 2.0 inter-rater reliability was explored using the Intra-Class Correlation Coefficient (ICC) equation $(2,1)$ [31] with a convenience sample of 18 formal caregivers who rated for 9 people with dementia ( 2 caregivers for each patient). The ICC values were calculated for each domain with their $95 \%$ confidence intervals $(\mathrm{Cl})$. The ICC was $0.97(95 \% \mathrm{Cl}=[0.87 ; 0.99])$ for cognition, 0.96 $(95 \% \mathrm{Cl}=[0.82 ; 0.99])$ for mobility, $0.83(95 \% \mathrm{Cl}=[0.32 ; 0.96])$ for self-care, $0.72(95 \% \mathrm{Cl}=[-0.16 ; 0.94])$ for getting along with people and $0.81(95 \% \mathrm{Cl}=[0.24 ; 0.96])$ for participation. These values indicated an excellent inter-rater reliability [31].

Parametric tests (i.e., Independent-Samples T test) were applied to compare the MMSE and WHODAS 2.0 total scores between genders. Parametric tests were chosen as the sample size was equal or higher than 30 subjects and data followed the normal distribution [32]. The non-parametric Kruskal-Wallis test was applied to compare the MMSE and WHODAS 2.0 total scores among 3 or more groups of the other variables (age, education, marital status, period of time living in the care facility, type of dementia and severity of cognitive impairment), as parametric requirements were not fulfilled, i.e., data did not followed the normal distribution and there was not equal variance between the groups [32]. The Kruskal-Wallis test was also used to analyse differences in the WHODAS 2.0 scores between the long-term care settings.

The correlation between the MMSE and WHODAS 2.0 total scores were also analysed with the Pearson coefficient $(r)$ [32]. The level of confidence $(\alpha)$ considered was 0.05 .

\section{RESULTS}

\section{Sample characterisation}

The mean age of people with dementia was $83.6 \pm 7.1$ years old (table1). Most were female $(n=262$; $79.6 \%)$, had low level of education, i.e., 1 to 4 years of education $(n=168 ; 51.1 \%)$ or no education $(n=97 ; 29.5 \%)$, were widowed $(n=200 ; 60.8 \%)$ and were living in the long-term care facility for less than 1 year $(n=105 ; 31.9 \%)$ or from 2 to 4 years $(n=119 ; 36.2 \%)$ (table1). One hundred and forty eight (45.0\%) participants did not have their type of dementia defined. From the people with dementia who presented a specific diagnosis, Alzheimer's disease was the most prevalent $(n=138 ; 41.9 \%)($ table1). 
Table 1: Characterisation of people with dementia living in long-term care facilities $(n=329)$.

\begin{tabular}{lrr}
\hline Variables (n=329) & $\mathbf{n}$ & $\%$ \\
\hline Age (years) & 3 & 0.9 \\
$50-64$ & 32 & 9.7 \\
$65-74$ & 136 & 41.3 \\
$75-84$ & 158 & 48.0 \\
\hline +85 & & \\
\hline Gender & 67 & 20.4 \\
Male & 262 & 79.6 \\
Female & & \\
\hline Years of education & 97 & 29.5 \\
Illiterate & 168 & 51.1 \\
1-4 & 17 & 5.1 \\
5-9 & 20 & 6.1 \\
+10 & 27 & 8.2 \\
Missing & & \\
\hline Marital status & 53 & 16.1 \\
Single & 61 & 18.5 \\
Married/Living with a partner & 15 & 4.6 \\
Divorced/Separated & 200 & 60.8 \\
Widowed & & \\
\hline Time of institutionalisation (years) & 105 & 31.9 \\
<1 & 119 & 36.2 \\
2-4 & 54 & 16,4 \\
5-7 & 27 & 8,2 \\
8-10 & 24 & 7,3 \\
\hline >11 & & \\
\hline Types of dementia & 148 & 45,0 \\
Unspecified dementia & 138 & 41,9 \\
Alzheimer Disease & 29 & 8,8 \\
Vascular Dementia & 8 & 2,4 \\
Dementia associated with Parkinson & 2 & 0,6 \\
Mixed Dementia & 2 & 0,6 \\
Fronto-temporal Dementia & 1 & 0,3 \\
Dementia with Lewy Bodies & 1 & 0,3 \\
Alcoholic dementia & & \\
\hline Cognitive impairment severity & 28 & 8,5 \\
Mild dementia (0-10) & 95 & 28,9 \\
Moderate dementia (11-20) & 203 & 61,7 \\
Severe dementia (21-27) & 3 & 0,9 \\
Not applicable & & \\
\hline & & \\
& & \\
& &
\end{tabular}

Formal caregivers' mean age was $45.2 \pm 10.3$ years old (table 2 ) and worked at the institution on average for $8.6 \pm 6.7$ years. Most were female $(n=162 ; 99.4 \%)$ had 5 to 9 years of education $(n=104$; $63.8 \%)$ and were married or living with a partner $(n=112 ; 68.8 \%)$ (table 2$)$.

Table 2: Formal caregivers socio-demographics $(n=163)$.

\begin{tabular}{lrr}
\hline Age (years) Mean \pm SD & 45.2 & 10.3 \\
\hline Time working at the institution Mean \pm SD & 8.6 & 6.7 \\
\hline & $\mathrm{n}$ & $\%$ \\
\hline Gender & & \\
Male & 1 & 0.6 \\
Female & 162 & 99.4 \\
\hline Years of education & & \\
$1-4$ & 27 & 16.6 \\
$5-9$ & 104 & 63.8 \\
+10 & 32 & 19.6 \\
\hline Marital status & & \\
Single & 19 & 11.7 \\
Married/Living with a partner & 112 & 68.8 \\
Divorced/Separated & 22 & 13.5 \\
Widowed & 10 & 6.1 \\
\hline
\end{tabular}




\section{Cognitive status}

According to the MMSE total scores, the cognitive status of people with dementia was on average low $(8.7 \pm 7.9)$ and $61.7 \%$ had severe cognitive impairment $(3.3 \pm 3.6)$ (table 1$)$.

The MMSE total score was influenced by age $(\rho=0.02)$, years of education $(\rho<0.001)$, time living in the facility $(\rho=0.04)$ and type of dementia $(\rho<0.001)$ (table 3$)$. More severe cognitive impairment tended to be found in people with more advanced age (i.e., $75-84$ or over 85 years old), less years of education, living in the long-term care facility from 2 to 4 years and presenting Alzheimer's disease.

Table 3: Differences in the MMSE and WHODAS 2.0 according to the characterisation variables of people with dementia $(n=329)$.

\begin{tabular}{|c|c|c|c|c|c|c|c|c|}
\hline \multirow[b]{2}{*}{ Characterisation variables } & \multicolumn{3}{|c|}{ MMSE } & \multirow[b]{2}{*}{$\rho$-value } & \multicolumn{3}{|c|}{ WHODAS } & \multirow[b]{2}{*}{$\rho$-value } \\
\hline & Mild & Moderate & Severe & & Mild & Moderate & Severe & \\
\hline \multicolumn{9}{|l|}{ Age } \\
\hline $50-64$ & 0 & 1 & 2 & & 0 & 1 & 2 & \\
\hline $65-74$ & 5 & 6 & 19 & $0.02^{*}$ & 2 & 9 & 21 & 0.05 \\
\hline $75-84$ & 15 & 45 & 75 & & 1 & 36 & 99 & \\
\hline+85 & 8 & 43 & 107 & & 1 & 23 & 134 & \\
\hline \multicolumn{9}{|l|}{ Gender } \\
\hline Males & 2 & 30 & 34 & 0,62 & 0 & 15 & 52 & 0.51 \\
\hline Females & 26 & 65 & 169 & & 4 & 54 & 204 & \\
\hline \multicolumn{9}{|l|}{ Years of education } \\
\hline Illiterate & 2 & 21 & 74 & & 0 & 17 & 80 & \\
\hline $1-4$ & 17 & 61 & 88 & $<0.001^{*}$ & 2 & 41 & 125 & 0.05 \\
\hline $5-9$ & 2 & 9 & 6 & & 1 & 3 & 13 & \\
\hline+10 & 4 & 2 & 14 & & 0 & 4 & 16 & \\
\hline \multicolumn{9}{|l|}{ Marital Status } \\
\hline Single & 3 & 17 & 32 & & 0 & 14 & 39 & \\
\hline Married/Living with a partner & 3 & 20 & 38 & 0.13 & 0 & 9 & 52 & 0.06 \\
\hline Divorced/Separated & 4 & 4 & 6 & & 1 & 6 & 8 & \\
\hline Widowed & 18 & 54 & 127 & & 3 & 40 & 157 & \\
\hline \multicolumn{9}{|c|}{ Time of institutionalisation (years) } \\
\hline$<1$ & 14 & 35 & 54 & & 2 & 34 & 69 & \\
\hline $2-4$ & 9 & 33 & 76 & & 1 & 19 & 99 & \\
\hline $5-7$ & 3 & 10 & 41 & $0.04^{*}$ & 0 & 9 & 45 & $<0.001^{*}$ \\
\hline $8-10$ & 1 & 9 & 17 & & 0 & 2 & 25 & \\
\hline$>11$ & 1 & 8 & 15 & & 1 & 5 & 18 & \\
\hline \multicolumn{9}{|l|}{ Type of dementia } \\
\hline Unspecified dementia & 17 & 50 & 79 & & 3 & 35 & 110 & \\
\hline Alzheimer Disease & 7 & 32 & 98 & $0.001^{*}$ & 1 & 28 & 109 & 0.11 \\
\hline Vascular Dementia & 1 & 9 & 19 & & 0 & 3 & 26 & \\
\hline Others & 3 & 4 & 7 & & 0 & 3 & 11 & \\
\hline \multicolumn{9}{|l|}{ Cognitive impairment severity } \\
\hline Mild & & & & & 1 & 15 & 188 & \\
\hline Moderate & NA & NA & NA & NA & 1 & 37 & 57 & $<0.001^{*}$ \\
\hline Severe & & & & & 0 & 16 & 11 & \\
\hline
\end{tabular}

\section{Activities and participation}

Table 4 illustrates the activities and participation of the people with dementia. 
There were no statistically significant differences $(\rho=0.196)$ in the WHODAS 2.0 scores between the different settings.

In general, people with dementia presented extreme disability or total inability in all questions of the domain 1 (cognition), with the exception of question 5, ("generally understanding what people say?"), where most people with dementia did not present difficulties $(n=105 ; 31.9 \%)$, or presented moderate difficulties $(n=90 ; 27.4 \%)$. Most people with dementia $(n=171 ; 52 \%)$ presented extreme difficulties or could not move by themselves (domain 2 - mobility). Extreme difficulties were also found in self-care (domain 3), when people with dementia have to wash themselves $(n=294 ; 89.4 \%)$ or get dressed $(n=258 ; 78.4 \%)$ however, most of them were able to eat without difficulty $(n=138 ; 41.9 \%)$. More than half of the people with dementia $(n=177 ; 53.8 \%)$ did not have difficulties in getting along (domain 4$)$ with people who were close to them. However, they presented severe or extreme disability in dealing with people they do not know, maintaining a friendship or making new friends.

In terms of participation (domain 6$)$, moderate disability ( $n=258 ; 78.4 \%)$ was found in most cases. It was observed that questions D6.2 ("How much of a problem the care recipient have because of barriers or hindrances in the world around him or her?") and D6.6 ("How much has his or her health been a drain on his or her financial resources or on the financial resources of other relatives?") were classified as "Not Known" ( $n=153 ; 46.5 \%$ and $n=253 ; 76.9 \%$ respectively), since caregivers did not feel they were informed about individual's exposure to personal barriers/hindrances or financial issues. In this domain, the majority of people with dementia did not present difficulties in the aspects covered by questions D6.3 ("How much of a problem did the care recipient have living with dignity because of the attitudes and actions of others?"), D6.4 ("How much time did the care recipient spend on his or her health condition, or its consequences?") and D6.5 ("How much has the care recipient been emotionally affected by his or her health condition?"). However, questions 1 and 8 showed that it was extremely difficult to join in community activities $(n=209 ; 63.5 \%)$ and doing things by themselves for relaxation and pleasure $(n=245 ; 74.5 \%)$.

The scores per domain showed that generally most participants had severe or extreme disability in all WHODAS 2.0 domains with the exception of the domain 6 (participation), where moderate disability was found. The total score of WHODAS 2.0 also confirmed the prevalence of severe disability $(n=256$; $77.8 \%)$. 
WHODAS 2.0 score was influenced by the period of time living in the facility $(\rho<0.001)$ and the severity of cognitive impairment $(\rho<0.001)$, i.e., longer period and higher severity was associated with higher activities limitation and participation restriction (table 4). Moreover, a significant negative correlation between the total score of the WHODAS 2.0 and the MMSE $(r=-0.69 ; \rho<0.001)$ was also found, meaning that as the cognitive ability decline the disability in the activities and participation increases.

Table 4: Activities limitation and participation restriction of people with dementia living in long-term care facilities $(n=329)$.

\begin{tabular}{|c|c|c|c|c|c|c|c|c|c|c|c|c|c|c|}
\hline \multirow{2}{*}{$\begin{array}{l}\text { Disability } \\
\text { Domain 1: Cognition }\end{array}$} & \multicolumn{2}{|c|}{ None } & \multicolumn{2}{|c|}{ Mild } & \multicolumn{2}{|c|}{ Moderate } & \multicolumn{2}{|c|}{ Severe } & \multicolumn{2}{|c|}{$\begin{array}{l}\text { Extreme or } \\
\text { cannot do }\end{array}$} & \multicolumn{2}{|c|}{ NA/NK } & \multicolumn{2}{|c|}{$\begin{array}{l}\text { Missing } \\
\text { values }\end{array}$} \\
\hline & $\mathbf{n}$ & $\%$ & $\mathbf{n}$ & $\%$ & $\mathbf{n}$ & $\%$ & $\mathbf{n}$ & $\%$ & $\mathbf{n}$ & $\%$ & $\mathbf{n}$ & $\%$ & $\mathbf{n}$ & $\%$ \\
\hline $\begin{array}{l}\text { D1.1 Concentrating on doing something for ten } \\
\text { minutes? }\end{array}$ & 46 & 14,0 & 12 & 3,6 & 53 & 16,1 & 31 & 9,4 & 177 & 53,8 & 10 & 3,0 & 0 & 0,0 \\
\hline D1.2 Remembering to do important things? & 20 & 6,1 & 8 & 2,4 & 22 & 6,7 & 16 & 4,9 & 257 & 78,1 & 6 & 1,8 & 0 & 0,0 \\
\hline $\begin{array}{l}\text { D1.3 Analysing and finding solutions to problems in } \\
\text { day-to-day life? }\end{array}$ & 38 & 11,6 & 8 & 2,4 & 19 & 5,8 & 20 & 6,1 & 244 & 74,2 & 0 & 0 & 0 & 0,0 \\
\hline $\begin{array}{l}\text { D1.4 Learning a new task, for example, learning how } \\
\text { to get to a new place? }\end{array}$ & 17 & 5,2 & 21 & 6,4 & 45 & 13,7 & 15 & 4,6 & 218 & 66,3 & 13 & 4,0 & 0 & 0,0 \\
\hline D1.5 Generally understanding what people say? & 105 & 31,9 & 24 & 7,3 & 90 & 27,4 & 67 & 20,4 & 35 & 10.6 & 8 & 2,4 & 0 & 0,0 \\
\hline D1.6 Starting and maintaining a conversation? & 65 & 19,8 & 23 & 7,0 & 69 & 21,0 & 31 & 9,4 & 140 & 42,6 & 1 & 0,3 & 0 & 0,0 \\
\hline TOTAL SCORE (6 items) & 0 & 0,0 & 11 & 3,3 & 81 & 24,6 & 165 & 50,2 & 72 & 21,9 & & & & \\
\hline Domain 2: Mobility & $\mathbf{n}$ & $\%$ & $\mathbf{n}$ & $\%$ & $\mathbf{n}$ & $\%$ & & $\%$ & $\mathbf{n}$ & $\%$ & $\mathbf{n}$ & $\%$ & $\mathbf{n}$ & $\%$ \\
\hline $\begin{array}{l}\text { D2.1 Standing for long periods such as } 30 \\
\text { minutes? }\end{array}$ & 51 & 15,5 & 12 & 3,6 & 25 & 7,6 & 15 & 4,6 & 222 & 67,5 & 4 & 1,2 & 0 & 0,0 \\
\hline D2.2 Standing up from sitting down? & 95 & 28,9 & 11 & 3,3 & 32 & 9,7 & 14 & 4,3 & 177 & 53,8 & 0 & 0 & 0 & 0,0 \\
\hline D2.3 Moving around inside their home? & 91 & 27,7 & 7 & 2,1 & 28 & 8,5 & 13 & 4,0 & 187 & 56,8 & 0 & 0 & 3 & 0,9 \\
\hline D2.4 Getting out of their home? & 68 & 20,7 & 4 & 1,2 & 13 & 4,0 & 4 & 1,2 & 232 & 70,5 & 8 & 2,4 & 0 & 0,0 \\
\hline $\begin{array}{l}\text { D2.5 Walking a long distance such as a kilometre [or } \\
\text { equivalent]? }\end{array}$ & 41 & 12,5 & 4 & 1,2 & 12 & 3,6 & 10 & 3,0 & 246 & 74,8 & 16 & 4,9 & 0 & 0,0 \\
\hline TOTAL SCORE (5 items) & 0 & 0,0 & 43 & 13,1 & 36 & 10,9 & 79 & 24,0 & 171 & 52,0 & & & & \\
\hline Domain 3: Self-care & $\mathbf{n}$ & $\%$ & $\mathbf{n}$ & $\%$ & $\mathbf{n}$ & $\%$ & & $\%$ & $\mathbf{n}$ & $\%$ & $\mathbf{n}$ & $\%$ & $\mathbf{n}$ & $\%$ \\
\hline D3.1 Washing his or her whole body? & 11 & 3,3 & 6 & 1,8 & 11 & 3,3 & 7 & 2,1 & 294 & 89,4 & 0 & 0 & 0 & 0,0 \\
\hline D3.2 Getting dressed? & 25 & 7,6 & 11 & 3,3 & 22 & 6,7 & 13 & 4,0 & 258 & 78,4 & 0 & 0 & 0 & 0,0 \\
\hline D3.3 Eating? & 138 & 41,9 & 11 & 3,3 & 40 & 12,2 & 21 & 6,4 & 118 & 35,9 & 1 & 0,3 & 0 & 0,0 \\
\hline TOTAL SCORE (3 items) & 0 & 0,0 & 10 & 3,0 & 27 & 8,2 & 176 & 53,5 & 116 & 35,3 & & & & \\
\hline Domain 4: Getting-along with people & $\mathbf{n}$ & $\%$ & $\mathbf{n}$ & $\%$ & $\mathbf{n}$ & $\%$ & & $\%$ & n & $\%$ & $\mathbf{n}$ & $\%$ & $\mathbf{n}$ & $\%$ \\
\hline D4.1 Dealing with people he or she does not know? & 99 & 30,1 & 20 & 6,1 & 48 & 14,6 & 38 & 11,6 & 113 & 34,3 & 11 & 3,3 & 0 & 0,0 \\
\hline D4.2 Maintaining a friendship? & 108 & 32,6 & 20 & 6,1 & 40 & 12,2 & 16 & 4,9 & 139 & 42,2 & 6 & 1,8 & 0 & 0,0 \\
\hline $\begin{array}{l}\text { D4.3 Getting along with people who are close to him } \\
\text { or her? }\end{array}$ & 177 & 53,8 & 20 & 6,1 & 47 & 14,3 & 16 & 4,9 & 67 & 20,4 & 1 & 0,3 & 1 & 0,3 \\
\hline D4.4 Making new friends? & 60 & 18,2 & 13 & 4,0 & 27 & 8,2 & 14 & 4,3 & 197 & 59,9 & 18 & 5,5 & 0 & 0,0 \\
\hline TOTAL SCORE (4 items) & 0 & 0,0 & 49 & 14,9 & 69 & 21,0 & 154 & 46,8 & 57 & 17,3 & & & & \\
\hline Domain 6: Participation & $\mathbf{n}$ & $\%$ & $\mathbf{n}$ & $\%$ & $\mathbf{n}$ & $\%$ & & $\%$ & $\mathbf{n}$ & $\%$ & $\mathbf{n}$ & $\%$ & $\mathbf{n}$ & $\%$ \\
\hline $\begin{array}{l}\text { D6.1 How much of a problem did the care recipient } \\
\text { have in joining in community activities (for example, } \\
\text { festivities, religious or other activities) in the same } \\
\text { way as anyone else can? }\end{array}$ & 56 & 17,0 & 9 & 2,7 & 36 & 10,9 & 12 & 3,6 & 209 & 63,5 & 7 & 2,1 & 0 & 0,0 \\
\hline $\begin{array}{l}\text { D6.2 How much of a problem the care recipient have } \\
\text { because of barriers or hindrances in the world } \\
\text { around him or her? }\end{array}$ & 110 & 33,4 & 10 & 3,0 & 28 & 8,5 & 23 & 7,0 & 5 & 1,5 & 153 & 46,5 & 0 & 0,0 \\
\hline $\begin{array}{l}\text { D6.3 How much of a problem did the care recipient } \\
\text { have living with dignity because of the attitudes and } \\
\text { actions of others? }\end{array}$ & 269 & 81,8 & 10 & 3,0 & 21 & 6,4 & 9 & 2,7 & 2 & 0,6 & 17 & 5,2 & 0 & 0,0 \\
\hline D6.4 How much time did the care recipient spend on & 184 & 55,9 & 38 & 11,6 & 48 & 14,6 & 12 & 3,6 & 0 & 0 & 47 & 14,3 & 0 & 0,0 \\
\hline
\end{tabular}




\begin{tabular}{llllllllll}
\hline $\begin{array}{l}\text { his or her health condition, or its } \\
\text { consequences? }\end{array}$ & & & & & & & & & \\
\hline
\end{tabular}

Legend: NA/NK - Not applicable or do not know.

\section{DISCUSSION}

The socio-demographics of the people with dementia were in agreement with previous studies, illustrating the predominance of people over 85 years old $[33,34]$, female, widows, with low level of education [27, 35-37] and living in the long-term care facility from 2 to 4 years [34]. Alzheimer's disease was the most prevalent type of dementia. A number of studies performed in different countries [38-41], including Portugal [37], suggested the same trend.

In terms of cognition, a low average score in the MMSE was found, following previous findings in long-term care facilities [33, 34]. Furthermore, 4 factors were associated with these scores: age, education, period of time living in the care facility and type of dementia. The association between the MMSE scores and age or education was consistent with the literature, i.e., more advanced age and lower education levels resulted in poorer MMSE results [35, 36, 42-45]. Presenting dementia and/or lower scores in cognitive tests have been suggested as an increased risk factor for long-term care placement $[46,47]$. Furthermore, lower scores are also associated with the natural course of dementia $[35,36,45]$. Therefore, it is expected that people who have been living longer in long-term care facilities present lower MMSE scores, explaining the findings of this study. The relationship between the MMSE scores and the type of dementia could be explained by the higher percentage of Alzheimer's disease patients in our sample, since previous research have reported that Alzheimer's disease was related with higher cognitive impairment (i.e., lower MMSE scores) than vascular dementia or dementia due to other etiologies [48].

Previous studies have reported that as dementia progresses, the cognitive impairment compromises peoples' activities and participation $[49,50]$. The WHODAS 2.0 results confirmed extreme difficulty in activities of daily living (self-care domain). However, despite the high levels of cognitive impairment, the participation domain was the least affected. Therefore, the authors hypothesise that formal 
caregivers might have an unclear notion of this domain, as their care is mostly targeted to instrumental activities (i.e., mobility, bathing, dressing, transferring and feeding). Thus, when caregivers are questioned about individuals' participation their answers might be mainly influenced by their experience in having the collaboration of people with dementia in activities of daily living [7]. Moreover, 3 questions of the domain 6 were found to be not applicable to our sample, which could have influenced the results. This should be clarified and further investigated. Nevertheless, improve function to increase the engagement of people with dementia in activities of daily living and avoid participation restrictions is one of the major goals of rehabilitation [30] and should be considered by health professionals [51].

In contrast, people with dementia presented the worse scores in the mobility domain. This result corroborated the findings of Dunlop et al. [52] which have suggested that walking is the most common disability in older people. Additionally, several studies have reported that people with dementia present shortened stride, reduced speed and heightened average limb support time, when compared with nondemented people $[53,54]$. These mobility limitations often increases caregivers' burden and leads to long-term care facilities admission [55] highlighting the need of rehabilitation. Several nonpharmacological interventions [51] have shown some potential in promoting mobility and preventing its decline in people with dementia however, further research is still needed.

Our results are in line with previous research in relation to extreme disability in cognition [56], bathing, dressing and transferring [52] among people with dementia living in long-term care facilities. However, in relation to feeding our findings were not consistent with previous research [52], as almost half of the participants with dementia were able to eat by themselves. This is in accordance with the studies of Morris et al. [57] and Njegovan et al. [58] which have suggested that the ability to eat tends to be lost later in the trajectory of Alzheimer's disease.

The total score of WHODAS 2.0 showed severe activities limitation and participation restriction in all the studied domains (i, ii, iii, iv and vi). This can be explained by the association between dementia and the increased loss of functionality $[40,59]$ and consequently, decline in activities and participation [50]. Additionally, the period of time living in the long-term care facility and the severity of the cognitive impairment were found to significantly affect the WHODAS 2.0 score. The association between the period of time living in the long-term care facility and the deterioration in cognitive and functional abilities has been previously reported $[60,61]$. Furthermore, higher severity of cognitive impairment 
was linked with increased disability in activities and participation [62, 63]. Therefore, the negative correlation found between WHODAS 2.0 and MMSE total scores confirmed that as the cognitive status deteriorates, the limitation in activities and restriction in participation increases [6, 9, 50, 62, 63]. This is an important result for rehabilitation, since it suggests that maintaining people with dementia involved in activities and participation could be a protective factor to delay cognitive decline [64, 65]. Therefore, this study contributes to a multidimensional knowledge on activities limitation and participation restrictions of people with dementia living in long-term care facilities to inform personcentred care in dementia, which has been strongly recommended in rehabilitation [14, 66-68].

\section{Limitations}

Some limitations of this study need to be acknowledged. There was a lack of medical records in the clinical files of the care facilities to confirm dementia and therefore, some people might not have been included in the study. This may have led to an underestimation of the number of cases of dementia included. This fact has already been mentioned by other studies $[33,34,56]$.

The use of the formal caregiver's perspective to assess activities limitation and participation restriction of people with dementia with the WHODAS 2.0 may be seen as a limitation. Hancock et al. [69] highlighted that the view of patients were not interchangeable by anyone, including the formal or informal caregivers. However, since a large number of people with dementia were unable to communicate, the caregiver's view to characterise these residents was deemed necessary. A way to overcome this barrier is to perform, when possible, a comparison between the perspectives of the caregivers and people with dementia, applying the WHODAS 2.0 respective versions to both [13]. This would result in a more comprehensive understanding of the needs of people with dementia and improved collaboration of people with dementia and caregivers $[15,69]$. Furthermore, the comparison between the perspectives of more than one formal caregiver, health professionals, formal and informal caregivers also seems to be important to validate WHODAS 2.0 results [13].

The several limitations associated with the use of the MMSE for assessing individuals with dementia are well described in the literature [42, 70, 71]. Scazufca et al. [42] have also suggested that the results of this instrument are strongly influenced by education and socio-demographic status, and the misclassification ratio for dementia cases is unacceptably high for older adults who are illiterate (which was a large percentage of the sample). Despite these justified criticisms, the MMSE was used to allow future comparisons with other studies, as it is the most used instrument to assess cognitive 
status. Moreover, it has been shown that MMSE is a reliable tool to use in people in advanced age [72]. Therefore, as almost half of the residents aged over 85 years old, it is believed that the limitations of its use were minimised [72].

\section{CONCLUSIONS}

This study shows that people with dementia living in long-term care facilities have severe activities limitation and participation restriction based on the WHODAS 2.0 (it includes cognition, mobility, selfcare, getting along with people and participation domains). Despite the severe activities limitation and participation restriction, most residents understand what people say, eat by themselves and get along with people who are close to them. These findings highlight that even people with extreme activities limitation and participation restriction have potential to perform some specific activities.This information on disability is crucial to plan health resources and inform rehabilitation programmes tailored to each person functionality.

\section{ACKNOWLEDGEMENTS}

The authors would like to acknowledge to all institutions, people with dementia and caregivers involved in this research.

\section{DECLARATION OF INTEREST}

The authors report no declarations of interest.

This study was funded by Portuguese National Funds through FCT - Foundation for Science and Technology through the grant number RIPD/CIF/109464/2009.

\section{REFERENCES}

1. Brookmeyer, R. and S. Gray, Methods for projecting the incidence and prevalence of chronic diseases in ageing populations: application to Alzheimer's disease. Statistics in Medicine, 2000. 19(11-12): p. 1481-1493.

2. Ritchie, K. and S. Lovestone, The dementias. The Lancet, 2002. 360(9347): p. 1759-1766.

3. Alzheimer Europe, A., World Alzheimer Report. Alzheimer's disease international. 2009.

4. Alzheimer Disease International, World Alzheimer Report: The benefits of early diagnosis and intervention., 2011: London, U.K.

5. National Institute for Health and Clinical Excellence, N.I.C.E., Dementia: the NICE-SCIE guideline on supporting people with dementia and their carers in health and social care. National Collaborating Centre for Mental Health: London, 2007. 
6. Sauvaget, C., et al., Dementia as a Predictor of Functional Disability: A Four-Year Follow-Up Study. Gerontology, 2002. 48(4): p. 226-233.

7. Liu, K.P.Y., et al., Activities of daily living performance in dementia. Acta Neurologica Scandinavica, 2007. 116(2): p. 91-95.

8. Carpenter, G., et al., Measuring change in activities of daily living in nursing home residents with moderate to severe cognitive impairment. BMC Geriatrics, 2006. 6(1): p. 1-8.

9. Kurz, X., et al., A new approach to the qualitative evaluation of functional disability in dementia. International Journal of Geriatric Psychiatry, 2003. 18(11): p. 1050-1055.

10. World Health Organization, W., World report on disability. 2011.

11. Hancock, S., Intermediate care and older people. Nursing Standard, 2003. 17(48): p. 45-51.

12. Scherer, M.J., Assessing the benefits of using assistive technologies and other supports for thinking, remembering and learning. Disabil Rehabil, 2005. 27: p. 731-739.

13. Ustun, T.B., et al., Measuring Health and Disability: Manual for WHO Disability Assessment Schedule - WHODAS 2.0. World Health Organization, 2010.

14. Brooker, D., Person-Centred Dementia Care: Making Services Better. 2007.

15. Crane-Ross, D., D. Roth, and B.G. Lauber, Consumers' and Case Managers' Perceptions of Mental Health and Community Support Service Needs. Community Mental Health Journal, 2000. 36(2): p. 161-178.

16. Linden, M., G. Gehrke, and B. Geiselmann, Profiles of recreational activities of daily living (RADL) in patients with mental disorders. Psychiatria Danubina, 2009. 21(4): p. 490-6.

17. WHO, W.H.O., International Classification of Functioning, Disability and Health (ICF). Geneva: WHO, 2001.

18. Cieza, A., et al., Identification of candidate categories of the International Classification of Functioning Disability and Health (ICF) for a Generic ICF Core Set based on regression modelling. BMC Medical Research Methodology, 2006. 6(1): p. 36.

19. Jennifer A., B., T. Travis T., and C. Margaret P., Influences on perceived function of a nursing home resident. Journal of Communication Disorders, 2003. 36(5): p. 379-393.

20. Donmez, L., Z. Gokkoca, and N. Dedeoglu, Disability and its effects on quality of life among older people living in Antalya city center, Turkey. Archives of Gerontology and Geriatrics, 2005. 40(2): p. 213-223.

21. Adib-Hajbaghery, M. and S. Aghahoseini, The evaluation of disability and its related factors among the elderly population in Kashan, Iran. BMC Public Health, 2007. 7(1): p. 261.

22. Sousa, R.M., et al., Measuring disability across cultures - the psychometric properties of the WHODAS II in older people from seven low- and middle-income countries. The 10/66 Dementia Research Group population-based survey. International Journal of Methods in Psychiatric Research, 2010. 19(1): p. 1-17.

23. Prince, M., et al., The association between common physical impairments and dementia in low and middle income countries, and, among people with dementia, their association with cognitive function and disability. A 10/66 Dementia Research Group population-based study. International Journal of Geriatric Psychiatry, 2011. 26(5): p. 511-519.

24. American Psychiatric Association, A., Diagnostic and statistical manual of mental disorders: DSM-IV. 1994. 4th ed.Washington, DC.

25. Folstein, M.S., S.E. Folstein, and P.R. McHugh, "Mini-mental state". A pratical method for grading the mental state of patients for the clinician. Journal Psychiatric Research, 1975. 12: p. 189-98.

26. Guerreiro, M., et al., Adaptação à população portuguesa do "Mini Mental State Examination" (MMSE). Revista Portuguesa de Neurologia, 1994. Supl. No 1: p. 9-10.

27. Fernandez, M., et al., Behavioural symptoms in patients with Alzheimer's disease and their association with cognitive impairment. BMC Neurology, 2010. 10(1): p. 87.

28. Miranda-Castillo, C., et al., Unmet needs, quality of life and support networks of people with dementia living at home. Health and Quality of Life Outcomes, 2010. 8(1): p. 132.

29. Simões, M.R., et al., WHODAS II. Versão Portuguesa Autorizada. Coimbra: Serviço de Avaliação Psicológica da Faculdade de Psicologia e de Ciências da Educação da Universidade de Coimbra., 2007.

30. World Health Organization, W., ICF Checklist. Geneva: World Health Organization. 2001.

31. Fleiss, J., Reliability of measurements. $1^{\circ} \mathrm{ed}$. The design and analysis of clinical experiments., ed. J. Fleiss1986, New York: John Wiley \& Sons.

32. Maroco, J., Análise Estatística com utilização do SPSS. 2003. $1^{\circ}$ edição.

33. Orrell, M., et al., A cluster randomised controlled trial to reduce the unmet needs of people with dementia living in residential care. International Journal of Geriatric Psychiatry, 2007. 22(11): $p$. $1127-1134$. 
34. Hancock, G.A., et al., The needs of older people with dementia in residential care. International Journal of Geriatric Psychiatry, 2006. 21(1): p. 43-49.

35. Paúl, C., O. Ribeiro, and P. Santos, Cognitive impairment in old people living in the community. Archives of Gerontology and Geriatrics, 2010. 51(2): p. 121-124.

36. Marra, T.A., et al., Influence of socio-demographic, clinical and functional factors on the severity of dementia. Archives of Gerontology and Geriatrics, 2010. In Press, Corrected Proof.

37. Nunes, B., et al., Prevalence and pattern of cognitive impairment in rural and urban populations from Northern Portugal. BMC Neurology, 2010. 10(1): p. 42.

38. Perkins, P., et al., Incidence and prevalence of dementia in a multiethnic cohort of municipal retirees. Neurology, 1997. 49(1): p. 44-50.

39. Bermejo-Pareja, F., et al., Incidence and subtypes of dementia in three elderly populations of central Spain. Journal of the Neurological Sciences, 2008. 264(1-2): p. 63-72.

40. Plassman, B.L., et al., Prevalence of Dementia in the United States: The Aging, Demographics, and Memory Study. Neuroepidemiology, 2007. 29(1-2): p. 125-132.

41. Savva, G.M., et al., Age, Neuropathology, and Dementia. New England Journal of Medicine, 2009. 360(22): p. 2302-2309.

42. Scazufca, M., et al., Limitations of the Mini-Mental State Examination for screening dementia in a community with low socioeconomic status. European Archives of Psychiatry and Clinical Neuroscience, 2009. 259(1): p. 8-15.

43. Kahle-Wrobleski, K., et al., Sensitivity and Specificity of the Mini-Mental State Examination for Identifying Dementia in the Oldest-Old: The 90+ Study. Journal of the American Geriatrics Society, 2007. 55(2): p. 284-289.

44. O'Bryant, S.E., et al., Detecting Dementia With the Mini-Mental State Examination in Highly Educated Individuals. Arch Neurol, 2008. 65(7): p. 963-967.

45. Anstey, K., et al., Estimates of probable dementia prevalence from population-based surveys compared with dementia prevalence estimates based on meta-analyses. BMC Neurology, 2010. 10(1): p. 62.

46. John, P.D.S., et al., Cognitive scores, even within the normal range, predict death and institutionalization. Age and Ageing 2002. 31: p. 373-378.

47. Wolstenholme, J.L., et al., Estimating the relationship between disease progression and cost of care in dementia. The British Journal of Psychiatry, 2002. 181(1): p. 36-42.

48. Gure, T.R., et al., Differences in Functional Impairment Across Subtypes of Dementia. The Journals of Gerontology Series A: Biological Sciences and Medical Sciences, 2010. 65A(4): $p$. 434-441.

49. Barberger-Gateau, P., et al., The Disablement Process: A Conceptual Framework for DementiaAssociated Disability. Dement Geriatr Cogn Dis, 2002. 13(2): p. 60-66.

50. Muò, R., et al., Alzheimer's disease-associated disability: An ICF approach. Disability and Rehabilitation, 2005. 27(23): p. 1405 - 1413.

51. Rabins, P.V., et al., APA Practice Guideline for the Treatment of Patients With Alzheimer's Disease and Other Dementias. 2007.

52. Dunlop, D.D., S.L. Hughes, and L.M. Manheim, Disability in activities of daily living: patterns of change and a hierarchy of disability. Am J Public Health, 1997. 87(3): p. 378-383.

53. Nakamura, T., et al., Postural and gait disturbance correlated with decreased frontal cerebral blood flow in Alzheimer disease. Alzheimer Dis Assoc Disord, 1997. 11: p. 132-139.

54. Goldman, W.P., et al., Motor dysfunction in mildly demented AD individuals without extrapyramidal signs. Neurology, 1999. 53: p. 956-962.

55. Pitkala, K., et al., Exercise rehabilitation on home-dwelling patients with Alzheimer's disease - a randomized, controlled trial. Study protocol. Trials, 2010. 11(1): p. 92.

56. Chung, J.C.C., Care needs assessment of older Chinese individuals with dementia of Hong Kong. Aging \& Mental Health, 2006. 10(6): p. $631-637$.

57. Morris, J.N., B.E. Fries, and S.A. Morris, Scaling ADLs within the MDS. J Gerontol A Biol Sci Med Sci, 1999. 54(11): p. 546-53.

58. Njegovan, V., et al., The hierarchy of functional loss associated with cognitive decline in older persons. J Gerontol A Biol Sci Med Sci, 2001. 56(10): p. 638-643.

59. van der Flier, W.M. and P. Scheltens, Epidemiology and risk factors of dementia. Journal of Neurology, Neurosurgery \& Psychiatry, 2005. 76(suppl 5): p. v2-v7.

60. Hatoum, H.T., et al., Predicting time to nursing home placement based on activities of daily living scores-a modelling analysis using data on Alzheimer's disease patients receiving rivastigmine or donepezil. J Med Econ., 2009. 12(2): p. 98-103. 
61. Wattmo, C., et al., Risk Factors for Nursing Home Placement in Alzheimer's Disease: A Longitudinal Study of Cognition, ADL, Service Utilization, and Cholinesterase Inhibitor Treatment. The Gerontologist, 2011. 51(1): p. 17-27.

62. Espiritu, D.A.V., et al., Depression, cognitive impairment and function in Alzheimer's disease. International Journal of Geriatric Psychiatry, 2001. 16(11): p. 1098-1103.

63. Marengoni, A., et al., Poor mental and physical health differentially contributes to disability in hospitalized geriatric patients of different ages. International Journal of Geriatric Psychiatry, 2004. 19(1): p. 27-34.

64. Mangialasche, F., et al., Dementia prevention: current epidemiological evidence and future perspective. Alzheimers Res Ther, 2012. 4(1): p. 6.

65. Nygard, L., Responses of persons with dementia to challenges in daily activities: a synthesis of findings from empirical studies. Am J Occup Ther, 2004. 58: p. 435-445.

66. National Institute for Health and Clinical Excellence, N.S. and N. National Collaborating Centre for Mental Health, NICE Guideline: Dementia Supporting people with dementia and their carers in health and social care. 2006.

67. World Health Organization, The World Health Report: Primary care Putting people first., 2008. p. 41-60.

68. van de Ven, G., et al., Improving person-centred care in nursing homes through dementia-care mapping: design of a cluster-randomised controlled trial. BMC Geriatr, 2012. 12(1): p. 1.

69. Hancock, G.A., et al., The needs of older people with mental health problems according to the user, the carer, and the staff. International Journal of Geriatric Psychiatry, 2003. 18(9): p. 803811.

70. Nishtala, P.S., et al., Determinants of antipsychotic medication use among older people living in aged care homes in Australia. Int J Geriatr Psychiatry, 2009. 25(5): p. 449-457.

71. Macdonald, A.J.D., Dementia and use of psychotropic medication in non-Elderly Mentally Infirm' nursing homes in South East England. Age and Ageing, 2002. 31(1): p. 58-64.

72. Alzheimer's Society, A., Reducing the use of antipsychotic drugs: A guide to the treatment and care of behavioural and psychological symptoms of dementia. Alzheimer's Society. London, 2011. 